\title{
Review
}

Volume 3 - Issue 3: 124-127 / July 2020

\section{THE EFFECT OF INSULIN SIGNALING PATHWAY ON HONEY BEE GROOMING BEHAVIOR}

\author{
Berkant İsmail YILDIZ1*, Kemal KARABAĞ²
}

\author{
${ }^{1}$ Akdeniz University, Graduate School of Natural and Applied Sciences, 07058, Antalya, Turkey \\ ${ }^{2}$ Akdeniz University, Faculty of Agriculture, Department of Agricultural Biotechnology, 07058 Antalya, \\ Turkey
}

Received: February 14, 2020; Accepted: March 13, 2020; Published: July 01, 2020

\begin{abstract}
The insulin signaling pathway is a highly conserved mechanism in vertebrate and invertebrate that regulates many physiological processes such as metabolism, growth and development. Insulin becomes functional after binding to insulin receptors in most tissues. Any disorder in the regulation of insulin release or downstream signaling leads to a variety of metabolic diseases including diabetes and obesity. In general, researchers have focused on the role of insulin signaling in metabolism, cell proliferation, development, growth and ageing, but the role of insulin in regulating insect behavior and interactions between neural circuits has been an interesting and neglected issue. In this review we focused on the possible effects of the insulin signaling pathway on grooming behavior in honey bees.
\end{abstract}

Keywords: Grooming behavior, Honey bee, Insulin signaling pathway, Nerve circuit

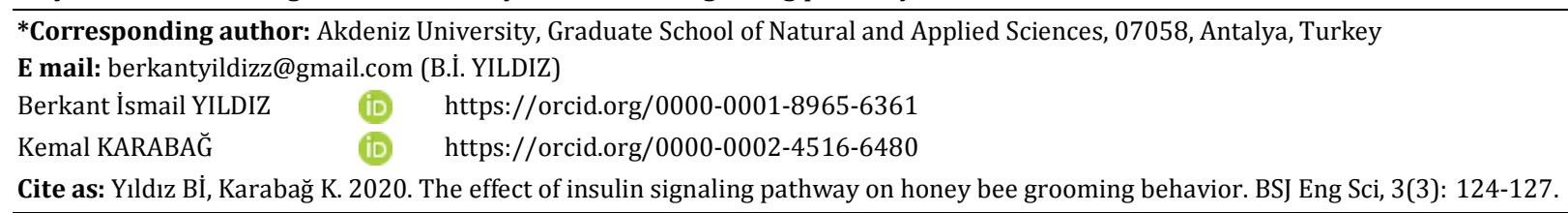

\section{Introduction}

Animals may perform the various behavior in response to their environment and internal state, and many movements are selected from a repertoire of stereotyped motor patterns (Hampel et al., 2015). This repertoire can include movements for different purposes, such as feeding, grooming, song production, locomotion, and even coordinated facial poses for expressing different emotions (Grillner and Wallen, 2004; Grillner et al., 2005). Many of these movements are produced by nerve circuits (Pearson, 1993; Kiehn and Kullander, 2004). Because most of the interaction between neurons in the nervous system occurs in synapses, changes in behavior are ultimately followed by changes in nature and the number of interneuronal synaptic contacts (Sweatt, 2016).

Grooming is a common behavior for getting rid of ectoparasites among vertebrates and arthropods (Aumeier, 2001). This behavior of bees has evolved to protect both individual and colony health (De Figueiró Santos et al., 2016). Grooming behavior is the ability of adult honeybees to remove mites from themselves or other bees (Kurze et al., 2016). Grooming behavior is named in two ways according to the way it is performed: auto-grooming or self-grooming and allogrooming or social grooming. Auto-Grooming is the self-cleaning behavior with the movement of mouthparts or pro- / 
mesothoracic legs. Allogrooming can be one-on-one, or socially involving several bees acting together. During social grooming, bees use their mouthparts to remove mite and debris of mite from the wing bases and other body parts of other bees (Milum, 1947).

Some studies have shown that grooming behavior provides resistance to against tracheal mites in European honey bees (Pettis and Pankiw, 1998; Danka and Villa, 2003; Villa, 2006) and Varroa mites in African bee populations (Moretto et al., 1993; Guzman-Novoa et al., 1999; 2002; Arechavaleta-Velasco and Guzman-Novoa, 2001; Mondragon et al., 2005; 2006).

In this study, the possible role of the insulin signaling pathway in grooming behavior was examined.

\section{Insulin Signaling Pathway and Effects on Insect Behavior}

Insulin plays a critical role in a wide range of biological processes, including stimulation of glucose uptake, glycogen, lipid and protein synthesis, anti-lipolysis, activation of transcription of specific genes, and modulation of cellular growth and differentiation (Taha and Klip, 1999).

The Insulin Signaling Pathway (ISP) agonists in insects are generally termed "insulin-like peptides" (ILPs) or "insulin-related peptides" (IRPs) (Badisco et al., 2013). The Insulin-like peptides (ILPs) of invertebrates have been described as functionally homologous to insulin and insulin-like growth factor 1 (IGF 1) ligands in mammals
(Flatt et al., 2005). In mammals, insulin is produced by beta-pancreatic cells and in insects, ILP is produced in neurons (Nilsen et al., 2011). Studies on insulin signaling in insects have covered the considerable distance with the identification of eight insulin-like genes in the fruit fly (Drosophila melanogaster) genome (Brogiolo et al., 2001; Grönke et al., 2010; Colombani et al., 2012). Although different ILPs are produced in different cell types and tissues at different stages of development, in all insects examined, at least one of the ILPs is produced by nerve cells in the brain (Nässel and Broeck, 2016).

Such as feeding and locomotor behavior are modulated through the insulin pathway by IPCs. Reduced insulin production from brain IPCs results in decreased downstream insulin signaling, leading to increased ethanol (EtOH) sensitivity and motivated foraging. With the decrease in insulin signaling in SNPFR (short Neuropeptide $\mathrm{F}$ receptor) expressing odor receptor neurons (ORNs) and NPFR (Neuropeptide F Receptor) expressing neuron enhances the sensitivity of ORNs to odors and increases the attractiveness of flies to harmful food sources. In locomotion, octopaminergic neurons signal to stimulate wake through IPCs. However, this effect is independent of insulin signaling. Insulin signaling in the corpus allatum (CA), an endocrine gland, triggers sexual dimorphism of locomotor structures. Finally, the insulin signaling in circadian small ventrolateral neurons (sLNVs) alters resting sensitivity (Figure 1) (Erion and Sehgal, 2013).

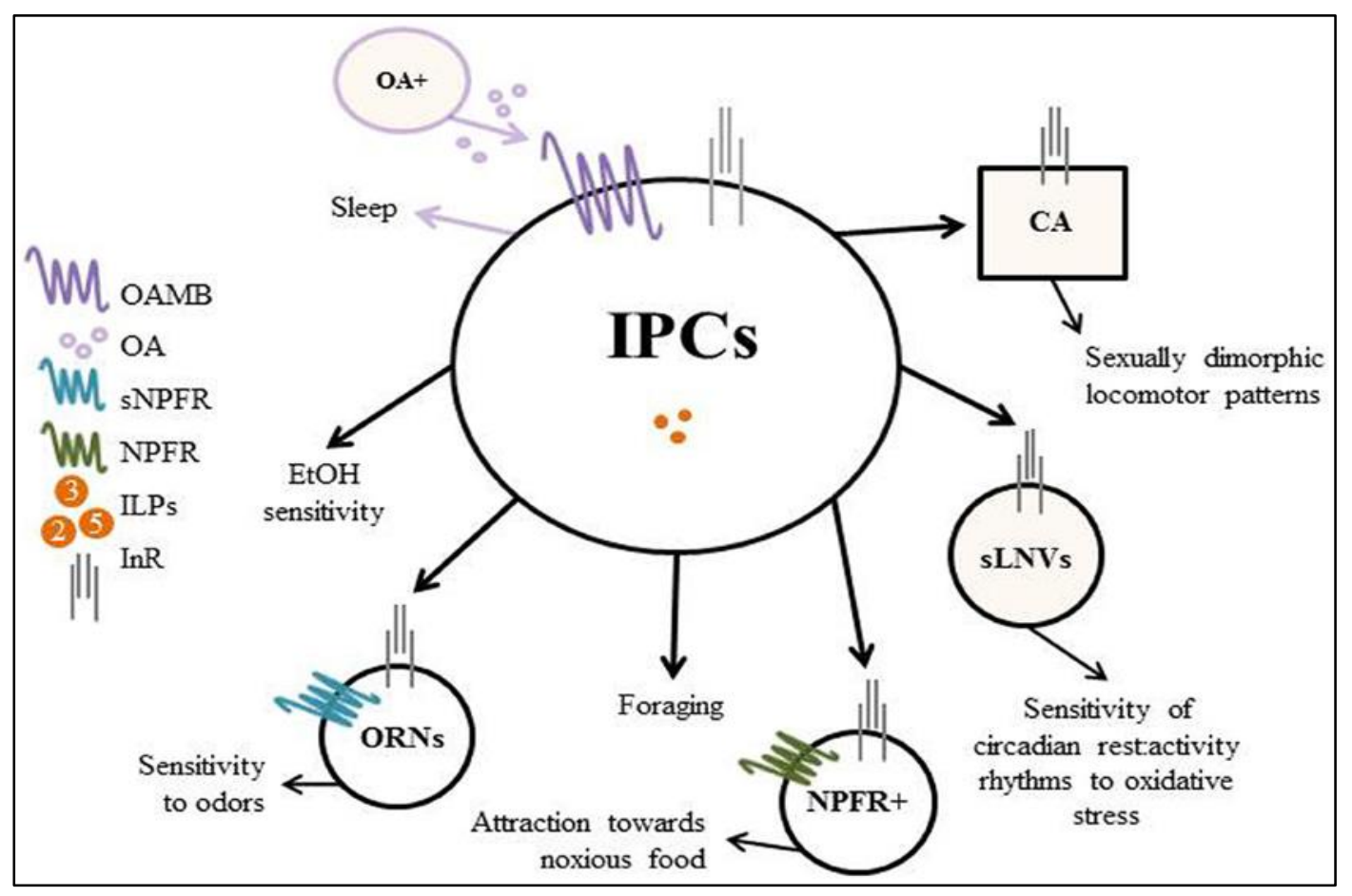

Figure 1. Regulation of behavior by insulin-producing cells (IPCs) in Drosophila (Erion and Sehgal, 2013).

$\mathrm{CA}=$ Corpus Allatum, ILPs= Insulin-Like Peptides, INR= Insulin Receptor, NPFR= Neuropeptide F Receptor, OA= Octopamine, $\mathrm{OAMB}=$ Octopamine Receptor, ORNs= Odorant Receptor Neurons, sLNVs= Small Ventrolateral Neurons, SNPFR= Short Neuropeptide F Receptor. 
Octopamine is an analog of norepinephrine found in invertebrates. The biogenic amine octopamine can act as a neurotransmitter, a neurohormone, and a neuromodulator (Farooqui, 2012). Neuromodulators can serve a specific behavioral context or a specific physiological state and establish mutual interactions between nerve tissues in metabolic or physiological states. Also, octopamine is activated energy sources in living organisms and causes an increase in activity in general (Roeder, 2005).

Octopamine has a great effect in regulating insect behavior, such as locomotion and grooming behavior in locusts, dance and sting behavior in honey bees, discrimination of nestmates from non-nestmates in honeybees and fire ants, division of labor and foraging preference in honey bee, visual responses in locusts and honey bees, learning and memory processes in honey bees, Drosophila melanogaster and Gryllus bimaculatus (Farooqui, 2012).

\section{Results and Discussion}

Mechanical or chemical stimuli cause movements that aim to remove foreign matter from the body surface (Newland, 1998; Page and Matheson, 2004; Reingold and Camhi, 1978; Canal et al., 1998; Honegger et al., 1979; Hensler, 1986; Phillis et al., 1996; Reingold and Camhi, 1977). In addition to environmental stimuli, different neurotransmitters and neural genes have been associated with the modulation of this behavior.

Fussnecker et al. (2006), in order to investigate the effect of biogenic amines on honey bee motor behavior, the honey bee workers have injected with octopamine, tyramine, mianserin and yohimbine in different concentrations. They followed the bees over a period of time to observe the effects of these treatments on walking, grooming, fanning and flying. Grooming behavior, at least to some degree, showed increased expression in four biogenic amine treatments.

Novikova and Zhukovskaya (2015), reported that octopamine generally did not affect the locomotor activity of cockroaches, but increased grooming behavior in the first half of the trial. In another study reported, increased levels of tyramine and decreased octopamine in Drosophila larvae cause abnormal locomotion (Saraswati et al., 2004). However, this abnormality is thought to be caused by defects in motor pattern formation (Fox et al., 2006).

Luo et al. (2014), found that knockdown of OAMB in IPCs affects certain physiological properties that may lead to a decrease in systemic IIS (Insulin/IGF Signaling), such as increased starvation and oxidative stress resistance and increased food intake in Drosophila.

When the studies are examined, octopamine appears to have a positive effect on the honey bee grooming behavior. It can be said that the effect of the insulin signaling pathway on grooming behavior may have an octopamine-dependent effect. However, it should be noted that there are difficulties in testing grooming behavior and that there are very few neurotransmitter studies related to grooming behavior.

It is clear that more information is needed about the interactions between insulin and the nervous system, which are responsible for the regulation of behavior. At the same time, more studies are also needed to understand the neurological basis of grooming behavior. Thus, the effect of insulin on grooming behavior will be more easily understood.

\section{Conflict of interest}

The authors declare that there is no conflict of interest.

\section{References}

Aumeier P. 2001. Bioassay for grooming effectiveness towards Varroa destructor mites in Africanized and Carniolan honey ees. Apidologie, 32: 81-90.

Arechavaleta-Velasco ME, Guzman-Novoa E. 2001. Relative effect of four characteristics that restrain the population growth of the mite Varroa destructor in honey bee (Apis mellifera) colonies. Apidologie, 32: 157-174.

Badisco L, Van Wielendaele P, Vanden Broeck J. 2013. Eat to reproduce: a key role for the insulin signaling pathway in adult insects. Front Physiol, 4: 202.

Brogiolo W, Stocker H, Ikeya T, Rintelen F, Fernandez R, Hafen E. 2001. An evolutionarily conserved function of the Drosophila insulin receptor and insulin-like peptides in growth control. Curr Biol, 11:213-221.

Canal I, Acebes A, Ferrús A. 1998. Single neuron mosaics of the Drosophila gigas mutant project beyond normal targets and modify behavior. J Neurosci, 18(3): 999-1008.

Colombani J, Andersen DS, Léopold P. 2012. Secreted peptide Dilp8 coordinates Drosophila tissue growth with developmental timing. Science, 336: 582-585.

Danka RG, Villa JD. 2003. Autogrooming by resistant honey bees challenged with individual tracheal mites. Apidologie, 34: 591-596.

De Figueiró Santos J, Coelho FC, Bliman PA. 2016. Behavioral Modulation of Infestation by Varroa destructor in Bee Colonies. Implications for Colony Stability. PLoS One, 11(9): e0160465.

Erion R, Sehgal A. 2013. Regulation of insect behavior via the insulin-signaling pathway. Front Physiol, 4: 353.

Farooqui T. 2012. Review of octopamine in insect nervous systems. Open Access Insect Physiol, 4: 1-17.

Flatt T, Tu MP, Tatar M. 2005. Hormonal pleiotropy and the juvenile hormone regulation of Drosophila development and life history. BioEssays, 27(10): 999-1010.

Fox LE, Soll DR, Wu CF. 2006. Coordination and modulation of locomotion pattern generators in Drosophila larvae: effects of altered biogenic amine levels by the tyramine $\beta$ hydroxlyase mutation. J Neurosci, 26(5): 1486-1498.

Fussnecker BL, Smith BH, Mustard JA. 2006. Octopamine and tyramine influence the behavioral profile of locomotor activity in the honey bee (Apis mellifera). J Insect Physiol, 52(10): 1083-1092.

Grillner S, Hellgren J, Menard A, Saitoh K, Wikstrom MA. 2005. Mechanisms for selection of basic motor programs-roles for the striatum and pallidum. Trends Neurosci, 28: 364-370.

Grillner S, Wallen P. 2004. Innate versus learned movementsa false dichotomy? Prog Brain Res, 143: 3-12.

Grönke S, Clarke DF, Broughton S, Andrews TD, Partridge L. 2010. Molecular evolution and functional characterization of 


\section{Black Sea Journal of Engineering and Science}

Drosophila insulin-like peptides. PLoS Genet, 6(2).

Guzman-Novoa E, Vandame R, Arechavaleta-Velasco ME. 1999. Susceptibility of European and Africanized honey bees (Apis mellifera L.) to Varroa jacobsoni Oud. İn Mexico. Apidologie 30: 173-182.

Guzman-Novoa E, Vandame R, Arechavaleta-Velasco ME, 2002. Tolerance to Varroa jacobsoni Oud. of honey bee (Apis mellifera L.) colonies in Mexico. In: Erickson, E., Page, R.E., Hanna, A.A. (Eds.), Proceedings of the 2nd Intern. Conf. Africanized Honey Bees \& Bee Mites. Root, Medina, OH, pp. 80-85.

Hampel S, Franconville R, Simpson JH, Seeds AM. 2015. A neural command circuit for grooming movement control. eLIFE, 4: e08758.

Hensler K. 1986. Intracellular recordings of neck muscle motoneurones during eye cleaning behaviour of the cricket. J Exp Biol, 120(1): 153-172.

Honegger HW, Reif H, Müller W. 1979. Sensory mechanisms of eye cleaning behavior in the cricket Gryllus campestris. J Comp Physiol A, 129(3): 247-256.

Kiehn O, Kullander K. 2004. Central pattern generators deciphered by molecular genetics. Neuron, 41: 317-321.

Kurze C, Routtu J, Moritz RF. 2016. Parasite resistance and tolerance in honeybees at the individual and social level. Zoology, 119(4): 290-297.

Luo J, Lushchak V, Goergen P, Williams MJ, Nässel DR. 2014. Drosophila insulin-producing cells are differentially modulated by serotonin and octopamine receptors and affect social behavior. PloS One, 9(6): e99732.

Milum VG. 1947. Grooming dance and associated activities of the honey bee. III Acad Sci Trans, 40: 194-196.

Mondragon L, Martin S, Vandame R, 2006. Mortality of mite offspring: a major component of Varroa destructor resistance in a population of Africanized bees. Apidologie, 37: 67-74.

Mondragon L, Spivak M, Vandame R. 2005. A multifactorial study of the resistance of honeybees Apis mellifera to the mite Varroa destructor over one year in Mexico. Apidologie, 36: 345-358.

Moretto G, Gonçalves LS, de Jong D. 1993. Heritability of Africanized and European honey bee defensive behavior against the mite Varroa jacobsoni. Rev Brasil Genet, 16: 7177.
Nässel DR, Broeck JV. 2016. Insulin/IGF signaling in Drosophila and other insects: factors that regulate production, release and post-release action of the insulin-like peptides. Cell Mol Life Sci, 73(2): 271-290.

Newland PL. 1998. Avoidance reflexes mediated by contact chemoreceptors on the legs of locusts. J Comp Physiol A, 183(3): 313-324.

Nilsen KA, Ihle KE, Frederick K, Fondrk MK, Smedal B, Hartfelder K, Amdam GV. 2011. Insulin-like peptide genes in honey bee fat body respond differently to manipulation of social behavioral physiology. J Exp Biol, 214(9): 1488-1497.

Novikova ES, Zhukovskaya MI. 2015. Octopamine, the insect stress hormone, alters grooming pattern in the cockroach Periplaneta americana. J Evol Biochem Phys, 51(2): 160.

Page KL, Matheson T. 2004. Wing hair sensilla underlying aimed hindleg scratching of the locust. J Exp Biol, 207(15): 2691-2703

Pearson KG. 1993. Common principles of motor control in vertebrates and invertebrates. Annu Rev Neurosci, 16: 265297.

Pettis JS, Pankiw T. 1998. Grooming behaviour by Apis mellifera L. in the presence of Acarapis woodi (Rennie) (Acari: Tarsonemidae). Apidologie, 29: 241-253.

Phillis R, Statton D, Caruccio P, Murphey RK. 1996. Mutations in the $8 \mathrm{kDa}$ dynein light chain gene disrupt sensory axon projections in the Drosophila imaginal CNS. Development, 122(10): 2955-2963.

Reingold SC, Camhi JM. 1978. Abdominal grooming in the cockroach: development of an adult behavior. J Insect Physiol, 24(1): 101-110.

Roeder T. 2005. Tyramine and octopamine: ruling behavior and metabolism, Ann. Rev. Entomol, 50: 447-477.

Saraswati S, Fox LE, Soll DR, Wu CF. 2004. Tyramine and octopamine have opposite effects on the locomotion of Drosophila larvae. J Neurobiol, 58(4): 425-441.

Sweatt JD. 2016. Neural plasticity and behavior-sixty years of conceptual advances. J Neurochem, 139: 179-199.

Taha C, Klip A. 1999. The insulin signaling pathway. J Membrane Biol, 169(1): 1-12.

Villa JD. 2006. Autogrooming and bee age influence migration of tracheal mites to Russian and susceptible worker honey bees (Apis mellifera L.). J Apicult Res, 45: 28-31. 